\section{Small Inflorescence Bulbils Are Best for Micropropagation and Virus Elimination in Garlic}

\author{
M. Ebi ${ }^{1}$, N. Kasai ${ }^{2}$, and K. Masuda ${ }^{3}$ \\ Department of Horticultural Sciences, Hokkaido University, Sapporo 060-8589, \\ Japan
}

Additional index words. Allium sativum, bolting, inflorescence, sprouting, tissue culture

\begin{abstract}
Garlic (Allium sativum L.) plants were cultured from immature inflorescence bulbils. The primordia of bulbils appeared initially as protuberances on reproductive apices, swelled, and then formed bulbils with protective leaves. Excised bulbils sprouted on Murashige and Skoog's medium with $5.4 \mu \mathrm{m}$ naphthaleneacetic acid (NAA) and grew into plantlets. The frequency of sprouting in culture increased with the development of bulbils before excision, and immature bulbils 0.4 to $2.4 \mathrm{~mm}$ in diameter sprouted at a frequency of $>85 \%$. A dot immunoblot assay revealed a remarkable reduction in levels of garlic mite-borne mosaic virus in plantlets grown from immature bulbils, suggesting that such bulbils might be suitable for the propagation of virus-free garlic plants.
\end{abstract}

Garlic is important in the preparation of food, as a condiment, and as a pharmaceutical. Most commercial varieties of garlic are sexually sterile and are usually propagated vegetatively from individual bulbs or cloves. Thus, the propagation factor in the fields is, at most, $6 \times$ to $10 \times$ per year. In addition, any virus infections are transferred to the next generation during vegetative propagation, with a possibly severe reduction in yield (Bohjwani et al., 1982; Conci and Nome, 1991). For the production of healthy seed bulbs, toxic viruses are usually eliminated from plants by shoottip culture of cloves, bulbs, or bulbils, and

We thank Dr. M. Inoue of Akita Prefectural Univ. for the gift of monoclonal antibodies, and Dr. T. Harada and M. Ito for many useful discussions. We are grateful to $\mathrm{H}$. Tamura, $\mathrm{C}$. Megumi, and $\mathrm{T}$. Kikuchi for their excellent technical assistance. The cost of publishing this paper was defrayed in part by the payment of page charges. Under postal regulations, this paper therefore must be hereby marked advertisement solely to indicate this fact.

${ }^{1}$ Graduate Student.

${ }^{2}$ Research Assistant

${ }^{3}$ Associate Professor; to whom reprint requests should be addressed (e-mail: kmasuda@ res.agr.hokudai.ac.jp) attempts to reduce infection in the field involve careful protection of plants from insects that vector disease.

Tissue culture techniques are used for the efficient propagation of garlic, using explants derived from root tips (Shuto et al., 1993), basal parts of the bulblets (Masuda et al., 1994), scape tips (Ma et al., 1994; Xue et al., 1991), shoot tips (Abo El-Nil, 1977; Bohjwani et al., 1982; Nagakubo et al., 1993; Verbeek et al., 1995), and leaves within cloves (Abo ElNil, 1977). Despite being sexually sterile, some varieties of garlic do bolt and produce large numbers of bulbils in their inflorescences. Some attempts have been made to use immature bulbils for propagation (Suh and Park, 1993). The mature bulbils may, however, be infected with viruses from the mother plant through the vascular tissues. They can also be infected by insect-borne viruses.

In this study, we characterized the development of bulbils, in terms of their morphology, in some clonal lines of completely bolting garlic. We examined the parameters for culture of immature bulbils, including their primordia, in an effort to establish a system for the propagation of healthy garlic plants. The presence of common viruses was monitored by immunological methods using monoclonal antibodies that recognize the various viruses.
Plant materials. The clonal lines 'Uru-b' and ' $\mathrm{Fc}$ ' of completely bolting garlic were used throughout the experiments. The lines were maintained vegetatively at the experimental farm of Hokkaido Univ., by sowing bulbs in late autumn (October) and harvesting in summer (August). On 16, 24, and 29 May; $3,10,17,24$, and 28 June; and 1 and 17 July 1998 , seven to 10 bulbs and flower stalks of 'Uru-b' and 'Fc' were sampled in the field and used for morphological characterization of the development of inflorescences and bulbils and for the culture of bulbils.

Tissue culture. Bulbs and whole spathes, including inflorescences, were surface-sterilized for $10 \mathrm{~min}$ with a solution of sodium hypochlorite (active chlorine, $1.0 \%$ ) that contained $0.2 \%$ Tween-20. After several rinses with distilled water, immature bulbils or primordia were removed aseptically. The diameters of bulbils and primordia were measured on micrographs. The explants were placed in $23 \times 135-\mathrm{mm}$ glass tubes (one explant per tube) containing $12 \mathrm{~mL}$ of media with inorganic salts and vitamins according to Murashige and Skoog (1962), 3\% sucrose, $0.8 \%$ agar, and $5.4 \mu \mathrm{M}$ NAA alone, or $54 \mu \mathrm{M}$ NAA combined with $0.89 \mu \mathrm{m}$ benzyladenine (BA). Each treatment consisted of 20 replicates and each experiment was repeated four times during the sampling dates indicated in Table 1 . The cultures were kept for 8 weeks at $23{ }^{\circ} \mathrm{C}$ with $16 \mathrm{~h}$ of light, at $\approx 40 \mu \mathrm{mol} \cdot \mathrm{m}^{-2} \cdot \mathrm{s}^{-1}$, daily from cool-white fluorescent tubes. In this report, we refer to the formation of shoots from bulbils and primordia as sprouting. Frequencies of sprouting were scored after culture of tissues for 8 weeks.

Scanning electron microscopy. Sample tissues were fixed and dehydrated as described by Jeffree and Read (1991). Dried samples were coated with platinum/palladium and examined with a scanning electron microscope (model E-1030; Hitachi, Tokyo).

Dot immunoblot assay: Monoclonal antibodies (MAbs) raised against Garlic Mosaic Virus (GMV), Garlic Mite-borne Mosaic Virus (GMMV), and Garlic Latent Virus (GLV) were kindly donated by Dr. M. Inoue (Akita Prefectural Univ.). Infection by viruses was examined by a dot immunoblot assay (DIBA) according to the method of Cuming et al. (1986) with a slight modification (Fig. 1), using MAb 9F6 for GMMV, MAb 10A4 for

Table 1. Development of bulbils, frequency of plantlet formation in bulbil cultures, and results of immunoblot assays (DIBAs) for detection of residual garlic miteborne mosaic virus (GMMV) in plantlets of clonal lines of garlic.

\begin{tabular}{|c|c|c|c|c|c|c|}
\hline \multirow[b]{3}{*}{$\begin{array}{l}\text { Sampling } \\
\text { date in } \\
1998\end{array}$} & \multicolumn{6}{|c|}{ Clonal line } \\
\hline & \multicolumn{3}{|c|}{ Uru-b } & \multicolumn{3}{|c|}{$\mathrm{Fc}$} \\
\hline & $\begin{array}{l}\text { Diam } \\
\text { of bulbils } \\
(\mathrm{mm})^{\mathrm{z}}\end{array}$ & $\begin{array}{l}\% \text { of explants } \\
\text { forming shoots } \\
\left( \pm \mathrm{SE}^{\mathrm{y}}\right)\end{array}$ & $\begin{array}{c}\text { DIBA on GMMV } \\
\text { (positive/ } \\
\text { total } / \% \text { ) }\end{array}$ & $\begin{array}{c}\text { Diam } \\
\text { of bulbils } \\
(\mathrm{mm})^{\mathrm{z}}\end{array}$ & $\begin{array}{l}\% \text { of explants } \\
\text { forming shoots } \\
\left( \pm \mathrm{SE}^{\mathrm{y}}\right)\end{array}$ & $\begin{array}{c}\text { DIBA on GMMV } \\
\text { (positive/ } \\
\text { total } / \% \text { ) }\end{array}$ \\
\hline 16-29 May & $0.34-0.43$ & $23.8 \pm 4.3$ & $0 / 16 / 0$ & $0.32-0.40$ & $21.3 \pm 5.5$ & $0 / 8 / 0$ \\
\hline 3-17 June & $0.42-2.4$ & $86.3 \pm 3.2$ & $0 / 9 / 0$ & $0.37-1.8$ & $88.8 \pm 3.1$ & $2 / 12 / 17$ \\
\hline 24 June-1 July & $2.2-5.3$ & $82.5 \pm 5.2$ & $8 / 12 / 67$ & $1.4-7.4$ & $86.3 \pm 4.3$ & $11 / 11 / 100$ \\
\hline 17 July & $5.0-5.4$ & $36.3 \pm 3.5$ & $3 / 3 / 100$ & $9.1-13.9$ & $20.0 \pm 3.5$ & $2 / 2 / 100$ \\
\hline
\end{tabular}

${ }^{\mathrm{z}}$ Minimum size-maximum size.

${ }^{y}$ Based on four replications, 20 explants cultured for each replication. 


\section{Propagation \& Tissue Culture}

A
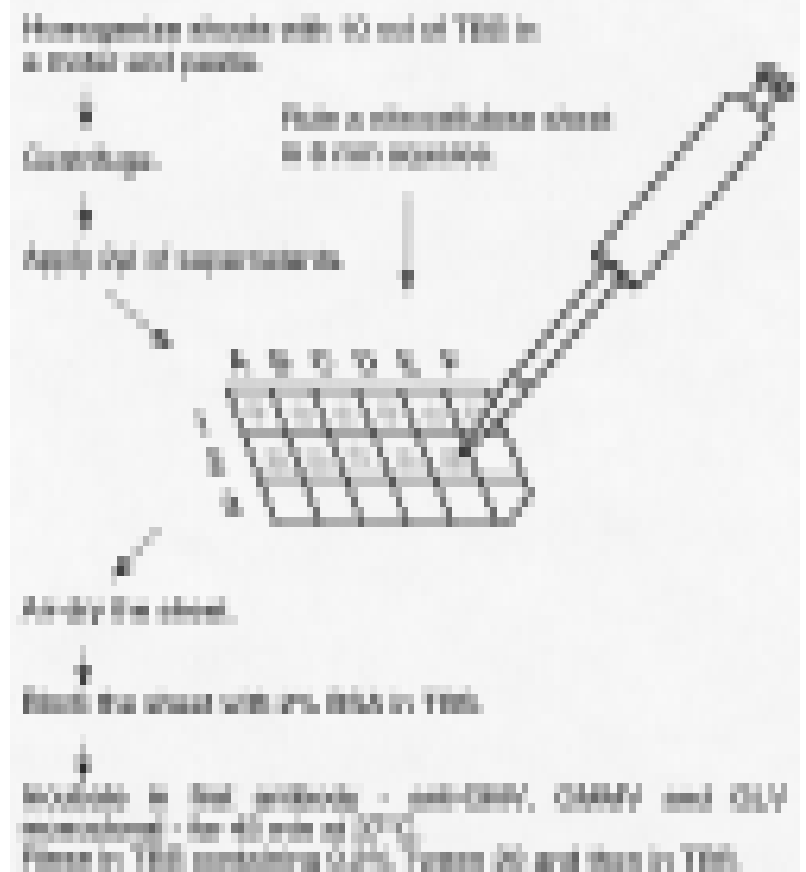

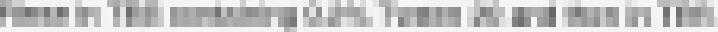
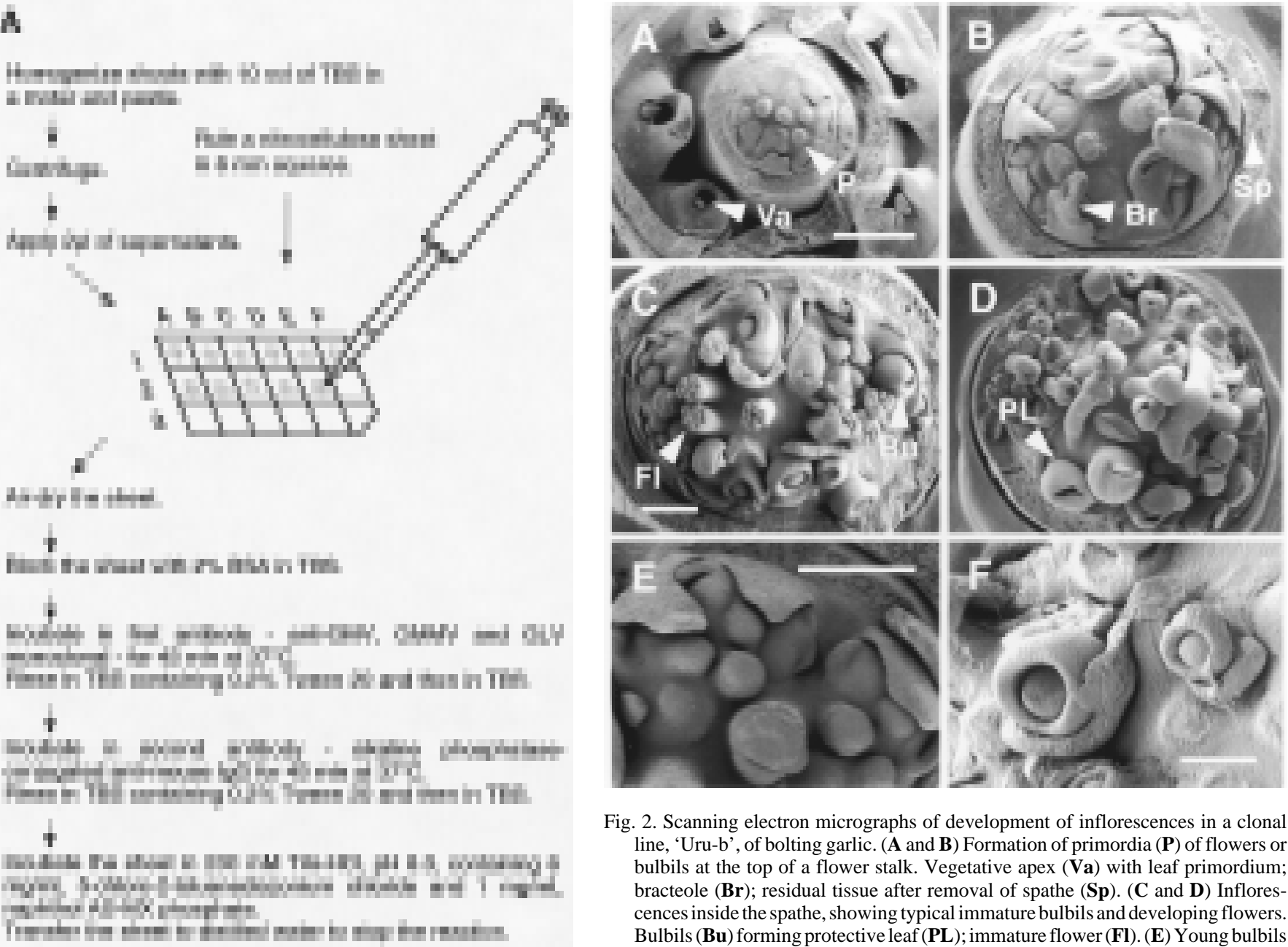

Fig. 2. Scanning electron micrographs of development of inflorescences in a clonal line, 'Uru-b', of bolting garlic. (A and $\mathbf{B}$ ) Formation of primordia $(\mathbf{P})$ of flowers or bulbils at the top of a flower stalk. Vegetative apex (Va) with leaf primordium; bracteole (Br); residual tissue after removal of spathe (Sp). (C and D) Inflorescences inside the spathe, showing typical immature bulbils and developing flowers. Bulbils $(\mathbf{B u})$ forming protective leaf $(\mathbf{P L})$; immature flower $(\mathbf{F l})$. (E) Young bulbils before differentiation of protective leaves. (F) Bulbils with protective leaves. Bars indicate $0.5 \mathrm{~mm}$ in $(\mathbf{A})$ and $(\mathbf{E})$, and $1.0 \mathrm{~mm}$ in $(\mathbf{C})$ and $(\mathbf{F})$.

H

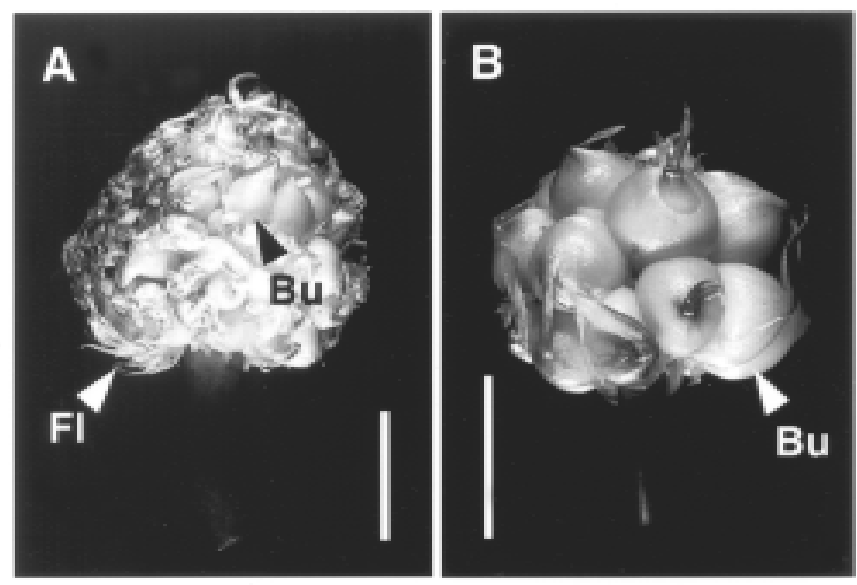

GMV and MAb 2E4 for GLV. Shoot tissues for assays were homogenized in 10 volumes of $20 \mathrm{~mm}$ Tris- $\mathrm{HCl}$ and $500 \mathrm{~mm} \mathrm{NaCl}$ [(Trisbuffered saline (TBS); $\mathrm{pH}$ 7.5] with a mortar and pestle. Cell debris was removed by centrifugation at $12,000 g_{\mathrm{n}}$ for 5 min in a microfuge. Aliquots of supernatants were spotted onto a nitrocellulose membrane and subjected to DIBA, with alkaline phosphatase-conjugated second antibodies. Products of immunoreactions were visualized by staining with 5 chloro-2-toluenediazonium chloride and naphthol AS-MX phosphate (Sigma, St. Louis).

Fig. 3. Mature inflorescences of clonal garlic lines 'Uru-b' and 'FC'. The inflorescences of (A) 'Uru-b' and (B) 'FC' were exposed by removal of the spathe. Bulbil (Bu); flower $(\mathbf{F l})$. Bars indicate $2.0 \mathrm{~cm}$.

'Uru-b' and ' $\mathrm{Fc}$ ' plants in the field were severely infected with a type of GMMV that was recognized with MAb 9F6, while the viruses recognized by MAbs 2E4 and 10A4 were not detected in our clonal lines of garlic. Therefore, in the present experiments, the infection of bulbil-derived plants was examined only with MAb 9F6.

\section{Results and Discussion}

Development of bulbils. Vegetative apices of 'Uru-b' with leaf primordia differentiated at the circumference of the basal region of seed bulbs (Fig. 2A) before the flower stalk begin to increase in length. At this developmental stage, several bracteole primordia and protuberances 
of primordia that would become bulbils and flowers, respectively, were visible on the reproductive apices of flower stalks (Fig. 2B). However, distinguishing bulbil primordia from flower primordia under the dissecting microscope was difficult.

Structural differences between the bulbil and flower primordia become apparent as inflorescences increased in size (Fig. 2C and D). Finally, the primordia of bulbils swelled (Fig $2 \mathrm{E}$ ) and formed bulbils, differentiating a bracteole and protective leaf that surrounded the apex of each bulbil (Fig. 2F). The flower primordia differentiated bracteoles and the flower stalks developed to connect each flower with a receptacle (Fig. 2D). The bulbils then grew rapidly to mature size. Upon maturation, bulbils reached an average of $5 \mathrm{~mm}$ ('Uru-b') and $12 \mathrm{~mm}$ ('Fc') in diameter (Fig. 3), and then stopped growing. 'Uru-b' plants produced an average of 46, and ' $\mathrm{Fc}$ ' plants 33 , bulbils.

Culture of bulbils. We excised immature bulbils of 'Uru-b' and 'Fc' aseptically from inflorescences and cultured them to promote sprouting. Primordia and immature bulbils with diameters $<0.43 \mathrm{~mm}$ ('Uru-b') and 0.40 $\mathrm{mm}$ (' $\mathrm{Fc}$ ') in diameter sprouted in culture at a low frequency (Table 1). A large fraction of the young explants generated calli and failed to form shoots. Some flower primordia included in explants formed flowers. The proportion of bulbils that sprouted in culture increased rapidly and reached a plateau value in both of 'URU-b' and 'Fc' with the development of bulbils. Bulbils with diameters 0.42$2.4 \mathrm{~mm}$ ('Uru-b') and 0.37-1.8 mm ('Fc') sprouted at frequencies $>85 \%$. Inclusion of NAA in the medium resulted in the development of thick shoots, but inclusion of $0.89 \mu \mathrm{M}$ benzyladenine (BA) together with $54 \mu \mathrm{M}$ NAA had no effect on the frequency of sprouting or on the appearance of the shoots. The sprouting bulbils rooted upon prolonged culture or after subculture on the same medium, and such bulbils regenerated complete plants (Fig. 4).

The frequency of sprouting of bulbils in culture decreased when the bulbils were almost fully mature (Table 1 ), probably as a result of initiation of dormancy. Intact mature bulbils cultured on MS medium that contained $54 \mu \mathrm{M}$ NAA with or without $0.89 \mu \mathrm{M}$ BA sprouted at frequencies of $48 \%$ to $56 \%$ depending on the line used, while the basal region excised from the bulbils sprouted at frequencies $>90 \%$ (data not shown).

DIBA of plants derived from bulbils. No GMMV was recognized with MAb 9F6 in plants derived from immature 'Uru-b' bulbils $<2.4 \mathrm{~mm}$ in diameter (Table 1). Bulbils of ' $\mathrm{Fc}$ ' $0.37-1.8 \mathrm{~mm}$ in diameter were rarely infected by the virus. Indeed, bulbils $<1.5 \mathrm{~mm}$ in diameter gave negative results in the DIBA with 9F6, while some extracts of plantlets derived from larger bulbils gave positive results. The MAb reacted with extracts of all well-developed bulbils that were close to the mature size. Thus, the bulbils appeared to be infected with internal viruses transferred from mother plants, via the tissues and vascular system, after bulbils had matured. Alternatively, infection might have occurred when external viruses were
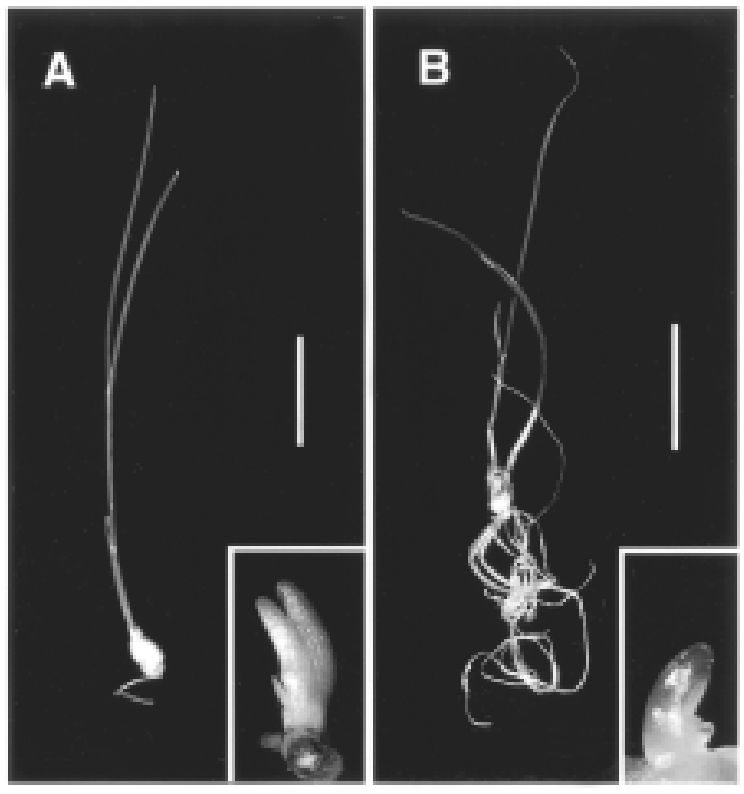

Fig. 4. Plantlets derived from excised bulbils of clonal lines (A) 'Uru-b' and (B) 'FC' of bolting garlic. Inserts in panels (A) and (B) show sprouting bulbils in culture. Bars indicate $2.0 \mathrm{~cm}$.

transferred by insects.

Verbeek et al. (1995) reported that the elimination efficiencies of viruses by meristem tip culture of garlic were $54 \%$ to $100 \%$, depending on the type of virus (Verbeek et al., 1995). Cunci and Nome (1991) demonstrated that the proportion of virus-free plants was improved by heat treatment combined with meristem tip culture. The results of DIBA showed that the efficiency of virus elimination by axenic culture using whole immature bulbils is comparable with that obtained by meristem tip culture. In addition, the present investigation demonstrates that immature bulbils of bolting garlic develop into plantlets in culture at high frequency. Therefore, although the application of our techniques is limited to the cultivars of garlic that bolt and produce inflorescence bulbils, such a system may be more convenient than shoot-tip culture.

GMMV is present in Japan and recently caused severe damage to garlic yields. The virus is transmitted by mites (Yamashita et al., 1996) and field infection is difficult to prevent. The system presented here might contribute to an increase in the production of virus-free seed bulbs, and thus reduce the number of virus-infected garlic plants in fields. In the future, the extent of infection by other types of viruses should be checked in a wide variety of garlic plants cultivated at other locations, and the present method should be tested for its ability to reduce the extent of infection.

\section{Literature Cited}

Abo El-Nil, M.M. 1977. Organogenesis and embryogenesis in callus culture of garlic (Allium sativum L.). Plant Sci. Lett. 9:259-264.

Bohjwani, S.S., D. Cohen, and P.R. Fry. 1982. Production of virus-free garlic and field performance of micropropagated plants. Scientia Hort. 18:39-43.

Conci, V.C. and S.F. Nome. 1991. Virus-free garlic
(Allium sativum L.) plants obtained by thermotherapy and meristem tip culture. J. Phytopathol. 132:186-192.

Cuming, A.C., R.S. Williams, and J.V. Cullimore. 1986. The use of antibodies in molecular biology, p. 137-154. In: T.L. Wang (ed.). Immunology in plant science. Cambridge Univ. Press, Cambridge.

Jeffree, C.E. and N.D. Read. 1991. Ambient- and low-temperature scanning electron microscopy, p. 313-346. In: J.L. Hall and C. Hawes (eds.). Electron microscopy of plant cells. Academic Press, Tokyo.

Ma, Y., H.-L. Wang, C.-J. Zhang, and Y.-Q. Kang. 1994. High rate of virus-free plantlet regeneration via garlic scape-tip culture. Plant Cell Rpt. 14:65-68.

Masuda, K., E. Hatakeyama, A. Ito, S. Takahashi, and M. Inoue. 1994. Micropropagation of garlic (Allium sativum L.). Bul. Akita Pref. College Agr. 20:43-48.

Murashige, T. and F. Skoog. 1962. A revised medium for rapid growth and bioassays with tobacco tissue cultures. Physiol. Plant. 15:473497

Nagakubo, T., A. Nagasawa, and H. Ohkawa. 1993. Micropropagation of garlic through in vitro bulblet formation. Plant Cell Tiss. Org. Cult. 32:175183

Shu, S.K. and H.G. Park. 1993. Rapid multiplication through immature bulbil cultures of garlic (in Korean). J. Korean Soc. Hort. Sci. 34:173-178

Shuto, H., T. Abe, and T. Sasahara. 1993. In vitro propagation of plants from root apex-derived calli in Chinese chive (Allium tuberosum Rottler) and garlic (Allium sativum L.). Jpn. J. Breed. 43:349-354

Verbeek, M., P. Van Dijk, and P.M.A. Van Well. 1995. Efficiency of eradication of four viruses from garlic (Allium sativum) by meristem tip culture. Eur. J. Plant Pathol. 101:231-239.

Xue, H.M., H. Araki, and T. Yakuwa. 1991. Varietal difference of embryonic callus induction and plant regeneration in garlic (Allium sativum $\mathrm{L}$.). Plant Tiss. Cult. Lett. 8:166-170.

Yamashita, K., J. Sasaki, and K. Handa. 1996. Characterization of a new virus from garlic (Allium sativum L.), garlic mite-borne mosaic virus. Ann. Phytopathol. Soc. Jpn. 62:483-489. 